\title{
(息)
}

Citation:

Carless, D and Douglas, K (2004) A Golf Programme for People with Severe and Enduring Mental Health Problems. International Journal of Mental Health Promotion, 3. 26 - 39. ISSN 1475-9535 DOI: https://doi.org/10.1108/17465729200400026

Link to Leeds Beckett Repository record:

https://eprints.leedsbeckett.ac.uk/id/eprint/1031/

Document Version:

Article (Published Version)

The aim of the Leeds Beckett Repository is to provide open access to our research, as required by funder policies and permitted by publishers and copyright law.

The Leeds Beckett repository holds a wide range of publications, each of which has been checked for copyright and the relevant embargo period has been applied by the Research Services team.

We operate on a standard take-down policy. If you are the author or publisher of an output and you would like it removed from the repository, please contact us and we will investigate on a case-by-case basis.

Each thesis in the repository has been cleared where necessary by the author for third party copyright. If you would like a thesis to be removed from the repository or believe there is an issue with copyright, please contact us on openaccess@leedsbeckett.ac.uk and we will investigate on a case-by-case basis. 


\section{A golf programme for people with severe and enduring mental health problems}

\section{ABSTRACT}

This article reports an experimental golf programme initiated for people with severe and enduring mental health problems partly to promote physical activity and partly as a socially inclusive activity. The programme was organised for a small, pilot group and evaluated using qualitative case study data collected during the programme. The success of the programme was indicated by the high attendance rates of participants, their voiced enthusiasm for the sessions and for the social interaction after the games, and the fact that many members of the first group continue to play and new members have joined the group, even though sessions are no longer being organised and paid for.

A substantial body of evidence now exists in support of the positive psychological effects of various forms of physical activity (Biddle et al, 2000; Department of Health, 2004; Morgan, 1997). Much of the existing literature has focused on people without diagnosed mental health problems or people with mild to moderate depression or anxiety. Only a small amount of research has explored the potential of physical activity for people with severe and enduring mental health problems and, at present, the therapeutic potential of physical activity for this client group is unresolved. However, as Faulkner and Biddle (1999) suggest in a review of the effects of exercise on schizophrenia, a growing body of research evidence suggests that physical activity can be effective in helping people with severe mental health problems cope with the difficulties their illness presents as well as helping to improve quality of life.

The distinction that emerges here, between treating a mental illness and improving mental health, is an important one. Tudor (1996) has argued that mental health and mental illness should be seen as two separate continua (Figure 1). This distinction allows the possibility of attaining positive mental health despite having a diagnosis of mental illness. On this basis, the promotion of mental health to individuals with a mental illness can be justified, regardless of whether or not their diagnosis improves.

\section{FIGURE 1 Mental health and mental illness} (Tudor, 1996)

Maximal mental Minimal mental disorder/illness disorder/illness

Minimal mental health

Optimum mental health

Moving the focus of service provision for people with mental health problems away from symptom removal towards promoting positive mental health is gaining growing support in both the clinical literature and within the user/survivor movement (Chadwick, 1997a; Repper \& Perkins, 2003). A predominant theme in user-led research is the importance of social networks, friendship, acceptance and opportunities to participate in and enjoy the same range of everyday activities as everyone else (Faulkner 2002, 1997; Mental Health Foundation, 2000; Wallcraft, 1998). Two important questions arise from this view. First, what kinds of service provision might help promote positive mental health and, second, how might we assess the success of a programme or intervention on 
the basis of positive mental health? Repper and Perkins (2003) provide a possible answer to both of these questions:

\section{In moving beyond symptoms and deficits, it is vital that we start in a different place: ie. with the voice of first hand experience. We need to begin by listening to people who have mental health problems. We must gain insight into the possibilities of life with a mental health problem.'}

In terms of service provision, activities that emphasise possibilities rather than problems are likely to be important and this is a key theme in the growing interest in a recovery, rather than a treatment, approach. Recovery is broadly described as 'a way of living a satisfying, hopeful and contributing life, even with limitations caused by the illness' (Anthony, 1993). Key themes in the recovery model include broadening clinical outcomes to include the goals of users: for example, for employment, independence, satisfying relationships and quality of life (Drake et al, 2001). This means re-thinking and expanding definitions of treatment to identify what an individual needs in order to regain or hold on to a life that has meaning for them, as well as enabling people to integrate more easily into society (Department of Health, 2001a).

Sport and exercise offers the potential of new forms of activity that might, in addition to helping improve physical and mental health, open up new lifestyle and other opportunities for service users. From the perspective of documenting and assessing the success of a physical activity programme, the responses to the programme of service users and mental health professionals offer an important starting point.

\section{Physical activity challenges}

There are a number of challenges that may arise when promoting physical activity to people with severe and enduring mental health problems:

- people with severe and enduring mental health problems often have poor physical health and fitness (Green $e t a l, 1999$ )
- a combination of physical fitness, psychological, and lifestyle issues are associated with low levels of physical activity (Brown et al, 1999)

- clinical disability, characterised by low levels of activity, slowed thought, slowed physical movement, flattened affect, apathy, poor speech, and social withdrawal (Childs \& Griffiths, 2003; Wing, 1978), hampers participation in physical activity

- social disability, resulting from behavioural disturbances (eg. difficulty relating to others, preoccupation with own thoughts, loss of social awareness) and cognitive impairment (eg. an inability to process information to meet the social expectations of others) (Childs \& Griffiths, 2003), hampers involvement in group activities.

As a result of these issues, the exercise adoption and adherence problems seen in the general population (Biddle \& Nigg, 2000) are likely to be more significant in this client group. Finally, mental health and other professionals may have low expectations and negative assumptions about the abilities of people with mental health problems, which can inhibit progress (Social Exclusion Unit, 2004). Creating the necessary motivation to overcome these problems, and successfully to initiate and maintain physical activity, is a key issue in mental health settings.

There are, however, several practical strategies that are likely to facilitate and encourage exercise adoption and adherence:

- choose a low-intensity physical activity to minimise physical demands. Walking groups, for example, have been found to be effective for this client group as the energy demands are minimal

- provide a supportive, non-competitive group environment

- provide opportunities for personal achievement, success, and progression

- provide the opportunity for social interaction and exchange.

One form of physical activity that may be appropriate to meet these needs, but has as yet been unexplored, is golf. 


\section{Golf for positive mental health}

There is some debate regarding the origins of the game of golf. Both the Dutch and the Scots have laid claim for introducing golf to the world. Regardless of its provenance, the fundamental tenets of the game have remained unchanged for centuries. The object is to hit a small ball with a club around a course and into a series of holes. To complete each hole the golfer putts the ball into a 4.25-inch hole. As the size of the modern golf ball is only 1.68 inches and the average course four miles long, the golfer needs a number of skills in order to play the game. These have been humorously described in the clubhouses of golf as a cross between the fine motor control of a surgeon, the explosive power of the sprinter and the tactics of a chess player. Notwithstanding this, one huge benefit of golf is that it can be extremely adaptable in terms of how the golfer performs the basic skill (ie. swinging the club) and in terms of the type and length of courses available. For example, the putt is a small, simple move requiring minimal strength or flexibility, yet most golf courses also have putting courses and many golfers enjoy this challenge as much as playing the longer full course. Although the average course is four miles long, there are numerous short courses around the country that are less than 2000 yards.

Another feature of the game is the wide range of types of game and playing facilities available around the country. These range from the seaside crazy golf courses costing as little as $£ 1$, through to driving ranges, short municipal courses and, finally, the exclusive private member golf courses costing hundreds of pounds to play. Undoubtedly the vast majority of golf is played on private member courses that are very exclusive and expensive, although the English Golf Union has recently introduced rule changes that reflect a move away from such 'member only' courses. Finally, golf permits unique opportunities for social interaction. Golf is perhaps the only sport where a male teenager will be seen playing with his grandmother - something that is unlikely in our other national sports of football, cricket and rugby. Age-wise, children as young as four play, and older people into their 90s are known to play.

\section{Golf and social inclusion}

The biggest problem with golf in a mental health context is, perhaps, not the technical requirements but its reputation for being elitist, sexist and (most recently) 'able-bodyist' (Maas, 2001). This is a major issue for people with serious mental health problems, for whom stigma and discrimination are already major concerns (Social Exclusion Unit 2004). Without doubt, at present, one would be ill advised to take any stigmatised group to most private member courses.

However, we believe that the increasing diversity of modern golf does offer a way in for many socially excluded groups; that there is a possibility to introduce people with mental health problems to golf and golf to people with mental health problems.

How, then, might golf contribute to social inclusion for people with severe and enduring mental health problems? First, sport is highly valued and viewed as socially significant in our society (Whitehead \& Corbin, 1997). It has also been described as an enduring element in the social and cultural life of most modern societies (McPherson et al, 1989), and an activity offering meaning and opportunity. As such, sport is an inescapably important part of life for many of us. Second, sport has been challenged recently by the government to make itself 'more socially inclusive' and less elitist (Cabinet Office, 2002). In this climate, can sport be used as a vehicle to challenge society's fear and ignorance of people with serious mental health problems and as a way to help them integrate with society? If so, how might we explore this possibility and what support and adjustments are necessary in the present era? Is it possible that golf - a sport that boasts one of the highest participation rates in the country might contribute to this goal? The remainder of this article sets out what we hope could be the beginning of this process.

\section{Aims of the research}

While both authors have an interest in investigating sport as a vehicle for social change as well as a way of promoting positive health benefits, the decision to introduce a golf programme was made only after much deliberation and discussion. Our priority was to ensure 
that we made every possible effort to avoid negative outcomes. While previous research (Carless, 2003; Faulkner \& Sparkes, 1999) has documented positive benefits from participation in various sports, including running, football, swimming and badminton, the benefits of playing golf for people with severe and enduring mental health problems have yet to be researched. Likewise, no research has been conducted to investigate the integration of minority groups into mainstream golf. Nor is there any information or guidance on coaching, playing and integration of this client group. We hope that this research will begin to fill that gap.

\section{Rationale for research methodology}

Faulkner and Biddle (1999) and Carless and Faulkner (2002) suggest that, for several reasons, randomised trials (RCTs) are not appropriate for physical activity research with this client group. This is, first, because RCTs require the control or elimination of some contextual factors (Miller \& Crabtree, 2000), and the resulting artificially sterile exercise experience may restrict the potential psychosocial benefits for participants. Specifically, the broad context in which physical activity takes place (including the social, environmental and mastery factors accompanying exercise) may be as important as the exercise itself in stimulating mental health change (Biddle et al, 2000; Fox, 1999). Second, it is questionable whether RCT designs allow researchers to access adequately the subjective value and meaning of participants' experience, which may be critical to mental health improvement (Repper \& Perkins, 2003). Third, because the mental health effects of physical activity are likely to vary from person to person (Fox, 1999), it is possible that a nomothetic (group means) analysis will mask individual change. Changes in group means do not necessarily reflect change at the individual level (see Van Landuyt et al, 2000). An ideographic approach (eg. Faulkner \& Sparkes, 1999) is well suited to capturing the individualised process of mental health change. Finally, in the context of this project, the small participant numbers would limit the value of any quantitative analysis.

Because of our desire to focus on the experiences of service users themselves and mental health improvement (rather than symptom removal), we chose a qualitative case study method, drawing on the principles of ethnographic research, to explore the responses to the golf programme both of service users and mental health professionals. This research approach allowed us to be open to diverse and unexpected factors that might affect the success of the programme. The primary research question was: Is this golf programme an activity that mental health service users and mental health professionals feel has a worthwhile place in the lives of these people with severe and enduring mental health problems?

\section{Method}

\section{Participants}

Nine men with severe and enduring mental health problems initially signed up to take part in the golf project. This number was consistent with available levels of staffing and transport.

\section{Recruitment}

The kinds of problems faced by this client group make the organisation and running of any activity group, particularly one that involves physical activity, very challenging. A common result is relatively low levels of attendance as group members may have poor motivation to join a new group, may experience unforeseen problems that prevent attendance, may simply forget about the group, or may be unable to get themselves to the meeting point. To deal with these problems in the context of the golf project, mental health staff actively recruited group members by displaying notices, contacting other mental health networks for suggestions of potential participants, publicising the golf group during other activities, and encouraging individual clients to take part. For the duration of the programme, group members were provided with free minibus transport, free entry to the golf facilities, free equipment, and free tea or coffee and biscuits after the session. Additionally, some were telephoned before each session to remind them, and others were collected from their homes. 


\section{Ethical approval and consent}

The research was granted ethical approval by the United Bristol Healthcare Trust as part of the first author's doctoral research. Ethical consent was sought from all participants, although they did not have to supply this in order to take part in the programme. Eight participants provided informed consent. In order to preserve anonymity the names of all clients, staff and places have been changed.

\section{Data collection}

Consistent with the case study method, data were collected through 'formal' semi-structured interviews with clients and mental health professionals, a focus group, 'informal' interviews with clients, and participant observation. One-to-one interviews were conducted by the authors and both authors participated in the focus group. Throughout the programme both authors kept independent field notes. Seven participants and four mental health professionals agreed to take part in 'formal' interviews, which were tape-recorded and transcribed verbatim by the first author. Two participants were uncomfortable with the use of a tape recorder and so were not interviewed, but one agreed to an 'informal' discussion. Data collection took place throughout the nine weeks of the programme and both authors attended the golf sessions as participant observers. A total of 14 interviews and one focus group were conducted with service users and mental health professionals.

\section{Data analysis}

Data were analysed in a five-stage process typical of qualitative data analysis (eg. Maykut $\&$ Morehouse, 1994; Miles \& Huberman, 1994). Both authors read and re-read the transcripts and field notes in order to become immersed in the data, and marginal notes, comments, and observations were made. The data were then coded and subjected to a content analysis, and key themes drawn from it, using quotations as the units of analysis. Throughout the analysis process the authors met regularly to compare and contrast their interpretations. Differences in interpretation were further scrutinised and explored by returning to the interview transcripts and field notes and through further discussion in an effort to reach agreement.

\section{The golf programme}

The nine-week golf programme was planned and designed by the second author, who is a qualified Professional Golfer's Association coach. Coaching input was provided throughout the programme, in line with our ethos of facilitating a positive golf experience for the group members. We sought to take the group from secure familiar territory into the less familiar, open golf environment, and to teach skills that made it possible for them not only to play the game but also to progress to playing on their own initiative. We felt it highly important that each member of the group was able to work at their own pace, that they weren't given too much technical information, and that the game was changed to ensure participation was a positive experiences and that their confidence was increased, especially in the early sessions. As with all golf coaching, encouraging an enjoyable, socially involving time was also important.

An outline of the full programme is shown in Table 1. We made several adaptations to the game during the programme. For example, in week one we tried to make the initial meeting less daunting by arranging an introductory talk over a cup of tea at the café in the day centre. The group then walked together to a nearby sports centre familiar to most of the group members where we had set up an indoor putting course by fixing masking tape to the carpet. This idea has been used in golf with beginner groups and children and has proved fun for the participants as well as rewarding in terms of personal achievement. Rather than use indoor putting cups, which are the same size as regular golf holes and difficult to putt into for beginners, we made scoring circles. The inner circle was approximately one foot in diameter, and scored 150 points; the middle circle was two foot in diameter and scored 100 points, and the outer circle was six foot wide and scored 50 points. The game was to get the ball to stop within the circles; the closer to the middle, the more points scored. To 


\begin{tabular}{|ll|}
\hline TABLE 1 The golf programme & \\
\hline Week one & $\begin{array}{l}\text { Social group meeting in day centre café } \\
\text { Indoor putting instruction and game }\end{array}$ \\
\hline Week two & Introductory driving range instruction and games \\
\hline Week three & Second driving range session - development \\
\hline Week four & $\begin{array}{l}\text { First on-course session (local par-3 course) } \\
\text { Introduction and Texas scramble game }\end{array}$ \\
\hline Week five & Third driving range session - revision \\
\hline Week six & 9 holes on par-3 course with instruction \\
\hline Week seven & 9 holes on par-3 course with instruction \\
\hline Week eight & Independent unguided play on par-3 course \\
\hline Week nine & Final free-play session on par-3 course \\
\hline
\end{tabular}

prepare the participants for actual play, the final circle was the size of a golf course hole, and scored 200 points. In line with our aim that this would be a team rather than individual activity, we played in groups of three. Each group had time for two rounds and all groups improved their score in the second round.

The driving range sessions (weeks 2, 3 and 5) took place at a local privately owned golf course. The owner made no special allowances for this group, although the staff were sensitive to the needs of the group and interacted easily with them. The sessions were taught as they might be for any other group of beginners, in allotted bays alongside members of the general public. In the first session the group were shown how to pay and collect baskets of balls from the dispenser, and had a short, whole-group lesson on basic grip, stance and short swing comprising demonstration and explanation of easy to remember steps that were verbally re-enforced during the afternoon. Each golfer was asked to work with one or two partners in an allocated driving bay, and to help each other remember the teaching points.
Each player was asked to hit five balls and then let their partner hit, while individual teaching instruction was provided. The organisation and coaching input were typical of any beginner group lesson, and no further alterations were needed for this group.

The golf course sessions (weeks 4, 6, 7, 8 and 9) took place at a local municipal par-3 course, which was chosen specifically for reasons of cost $(£ 5$ a round, including equipment); access (we used a minibus but participants could walk there if they wanted to play independently); there was a place to socialise after play, and refreshments, and there were no restrictions on dress, equipment or playing standard.

During these sessions individual members of the group were encouraged to play at their own pace and decide how many holes they played. If any member found a hole difficult, they were encouraged to pick the ball up and move on. These adaptations to the traditional form of golf, along with all other teaching input and support during the programme, represents 
good professional practice and is common to work with all beginner groups.

\section{Discussion of findings}

A key criteria for assessing the success of any programme is attendance. The day-to-day difficulties faced by people with severe and enduring mental health problems, combined with the challenge of a new form of physical activity, can result in poor and sporadic attendance figures. In the words of Mandy, an occupational therapist: 'In rehab, a group is more than one.' From this perspective, the attendance figures for the golf programme were surprisingly good. Allowing for planned absences (eg. attendance at college courses), the overall attendance was $80 \%$ (Table 2).

We would argue that, in a mental health promotion setting, attendance provides a clear demonstration of service users' response to the programme. To coin a phrase, 'people vote with their feet'. As Angela, a carer of one participant, said:
I have very positive feelings towards it the golf programme] I think, on the whole, because it seemed to go well. From the start it seemed to get a good response from the clients. I think that was where my positive feelings came from. They responded to it and they came back week after week.'

Julian, an exercise leader, was similarly positive when we asked him for his views on the levels of participants' attendance:

I thought it was amazing really - and how long it lasted for, to be honest. I know when I left there was a slight dip, one or two dropped out, but overall the attendance was brilliant.'

Given its significance in reflecting service users' responses to the golf programme, we analysed the data in order to identify and explore the specific factors that influenced attendance. The key themes are illustrated in Figure 2 and discussed in more detail below.

\section{TABLE 2 Attendance at golf programme}

\begin{tabular}{|c|c|c|c|c|c|c|c|c|c|}
\hline & Wk 1 & Wk 2 & Wk 3 & Wk 4 & Wk 5 & Wk 6 & Wk 7 & Wk 8 & Wk 9 \\
\hline Jerry & $\checkmark$ & $\checkmark$ & $\checkmark$ & $\checkmark$ & $\checkmark$ & $\checkmark$ & $\checkmark$ & $\checkmark$ & $\checkmark$ \\
\hline Peter & $\checkmark$ & $\checkmark$ & $\checkmark$ & $\checkmark$ & $\checkmark$ & $\checkmark$ & $\checkmark$ & & $\checkmark$ \\
\hline Richard & \multicolumn{2}{|c|}{ On college course } & $\checkmark$ & $\checkmark$ & $\checkmark$ & $\checkmark$ & $\checkmark$ & $\checkmark$ & $\checkmark$ \\
\hline Andrew & $\checkmark$ & $\checkmark$ & $\checkmark$ & $\checkmark$ & $\checkmark$ & $\checkmark$ & $\checkmark$ & \multicolumn{2}{|c|}{ On college course } \\
\hline Ali & & $\checkmark$ & $\checkmark$ & $\checkmark$ & & & & & \\
\hline Ronnie & $\checkmark$ & $\checkmark$ & & & $\checkmark$ & $\checkmark$ & & $\checkmark$ & $\checkmark$ \\
\hline William & $\checkmark$ & & & $\checkmark$ & & $\checkmark$ & & $\checkmark$ & $\checkmark$ \\
\hline Chris & \multicolumn{4}{|c|}{ On college course } & $\checkmark$ & $\checkmark$ & $\checkmark$ & $\checkmark$ & $\checkmark$ \\
\hline Harry & $\checkmark$ & $\checkmark$ & $\checkmark$ & $\checkmark$ & & $\checkmark$ & & & $\checkmark$ \\
\hline
\end{tabular}




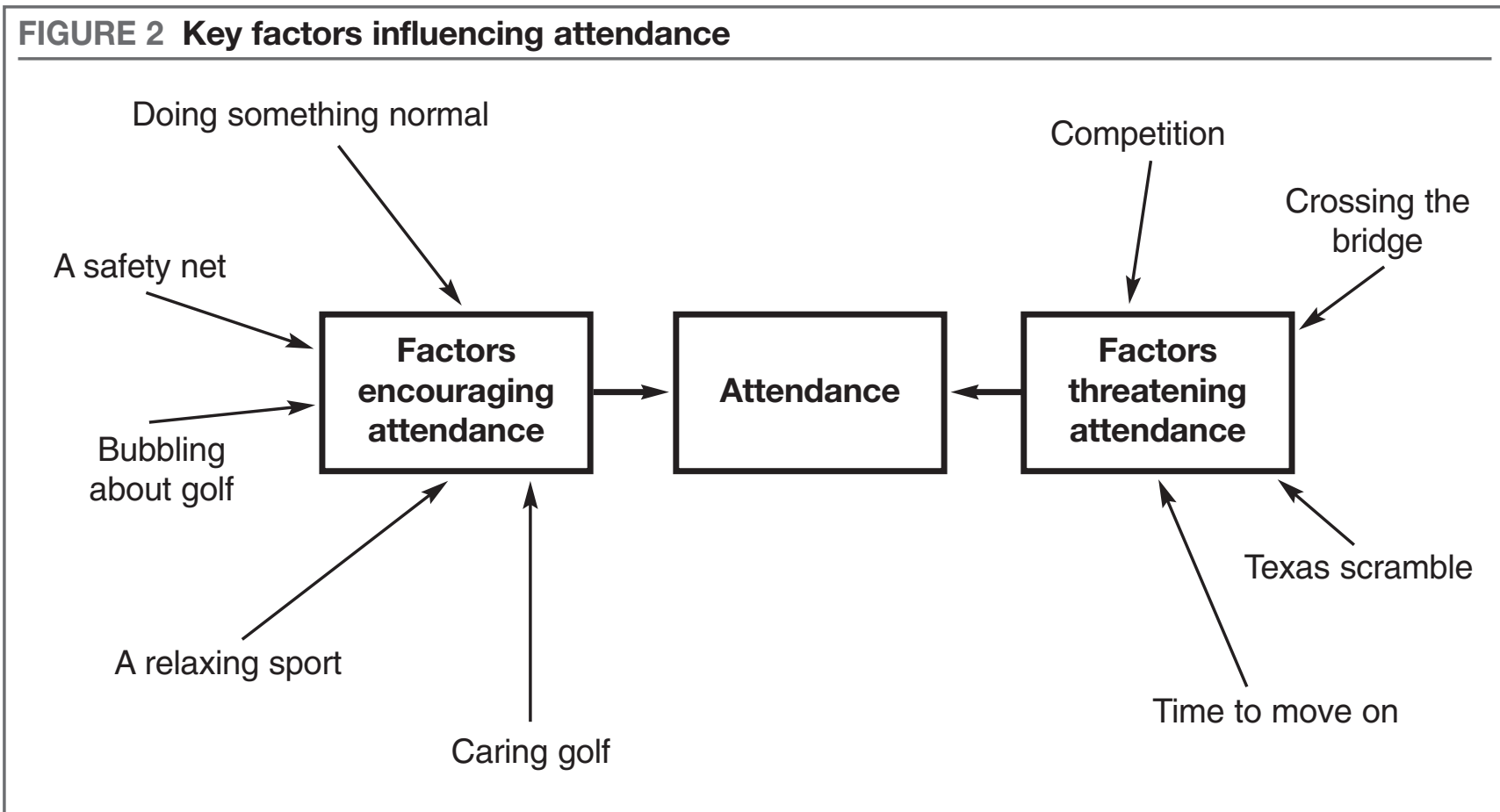

\section{Factors encouraging attendance}

\section{A safety net}

Initially, we organised and prompted most aspects of the programme: the location, the amount of coaching, the length of the sessions and the activities during the sessions. We decided how many holes were to be played and which players were in which group. This close support provided participants with a 'safety net', which was important in three ways. First, support from mental health professionals in the form of phone calls and transport was necessary to encourage initial attendance and to help participants make their way to the sessions each week:

'There were two clients of mine, and two of Katie's [a carer] that we had to phone up just to basically remind them - they wouldn't come... But that's the norm with those two, they've got to be reminded... Just to encourage them really and remind them. I think it's just a safety net to let them know it's on.' (Julian)

Second, that the golf programme was free encouraged attendance among individuals with limited disposable income. In Julian's words:
'Money is a major thing - they wouldn't go out and do it 'cause of money basically. Yeah, one comment was [that] they wouldn't do this because it would cost too much and they wouldn't be able to afford it.'

Third, a fairly directive coaching style helped participants to achieve immediate improvement in terms of the technical skills of the game:

I do think the fact that you were there with your obvious knowledge and coaching skills, I do think that was a very important part of the positive responses because people were able to see an improvement because you were able to be quite directive and say: "This is what you do, this is what you need to do, this is what you're not doing." You know, you could see all that. And I think that was a very valuable part of it, that kind of direction really.' (Angela)

\section{Transferring responsibility}

Over the course of the first few sessions responsibility was gradually transferred from the organisers to the participants. For example, on the group's first trip to the golf course, having organised play for the first two holes, David recorded in his field notes: 'There was little else 
for me to do as, for the most part, the three participants knew what was going on and the game needed minimal intervention' (DC field notes, 25 June). By week seven, most group members could cope without the need for direction from the organisers:

\section{'Before I approached the next pair, I watched for five minutes from $50 \mathrm{~m}$ away. They were both appearing to get on well with each other and their game. I saw Jerry play a good tee shot on the 5th. It led me to wonder whether my presence with each pair dismupted their natural play and interaction as Jerry and Peter seemed so at ease.'(DC field notes, 16 July).}

By the end of the programme Katie felt some of the participants were sufficiently confident of the situation to consider continuing to play golf when the organised sessions finished:

'Peter said to me last week that it's given him the incentive to come out and do it on his own, come out and play again. 'Cause I think he's played before but it had gone by the wayside. He said, you know, "I've really enjoyed it and I want to continue," so I said, "Will you come up on your own?" and he said, "Oh yeah, definitely." So that's really nice.'(Katie)

\section{Bubbling about golf}

The comments of mental health professionals suggest that the golf programme generated an unusual degree of enthusiasm. In Julian's words:

'The days after [the golf sessions] they were still bubblingsort of, their enthusiasm about it - especially in the first three sessions. Like Andrew was saying after the first session, "That golf was really good!" 'Cause I missed the putting, and he said, "You weren't at the putting - you missed a good session there!" And I must admit... he wouldn't have said that before. He wouldn't have said it that enthusiastically.'

According to the staff, this enthusiasm seemed to spread through the centre and affected other clients:
'When clients [who] were on the group said, "I'm doing golf," there's other people said, "Oh, I want to try that!" And it would go like that... It seems it got people's imagination. It's something totally different I think.' (Julian)

Perhaps linked to the clients' enthusiasm and interest was a degree of certainty that Angela felt was unusual:

\section{I did hear the word "definitely" used when [we asked] "Are you gonna go this week?" and "Did you enjoy it?" The word definitely was used a number of times, which is quite a firm word - for an erratic client group, it's quite a definite response.'}

In addition to enthusiasm spreading among the clients, other staff at the centre responded positively to the programme:

\section{"All the feedback from Claire [clinical psychologist] and Don [centre manager] and Mandy has been really, really positive. They were really surprised.' (Julian)}

Even André, an occupational therapy assistant who was not involved in the project, heard from the clients about the new golf programme:

'They [the group members] seem to be really enjoying it - I talk to them in the cafe. The general feeling was that it was really, really well-accepted and people really, really enjoyed it.'

\section{A relaxing sport}

The low intensity of golf as a form of physical activity was considered by clients and staff to encourage continued attendance. One of the participants, Andrew, described why he felt positive from the outset about joining the golf group:

I Ifelt keen, you know, 'cause I felt it was good time out and, you know, it's not as if I'm playing a hectic sport, it's pretty relaxed... It looked a very relaxed style sport - that's the beauty of it.' 
Peter similarly found the game relaxing: '

Last week was lovely 'cause I felt quite relaxed. Although I didn't hit the ball very well, I found it relaxing.'

These feelings were echoed by the mental health professionals. For example, André highlighted the importance of a low intensity exercise for this client group:

I think the good thing about golf is, in some ways, it's not too over-physical. Because you get a lot of people with sideeffects of the medication, putting on weight, for them to go swimming or them to go to football, or for them to do those sorts of activities is even harder because of all the excess weight they carry.'

\section{Caring golf}

From the outset, our aim was to provide a beneficial physical activity experience for the participants. As previously discussed, we organised the sessions with this specific aim in mind. The comments from mental health professionals and our own observations suggest that we successfully created an atmosphere of 'caring golf'. As David wrote in his field notes:

'The positive atmosphere was complemented by a large amount of consideration for each other. There really was, once again, no feeling of competitiveness. Everybody seemed to want everybody else to do well. Ronnie asked the group, "Can I go next, do you mind?" and Andrew replied, "No objections at all." Simple things, but positive, supportive, encouraging, and considerate.' (DC field notes, 9 July)

Katie linked the positive atmosphere to an absence of competition between group members:

\footnotetext{
It [golf] is not a competitive sport. You can play competitively, but when you're doing it in that sort of setting it's not competitive so everybody worked at their own pace and they improved at their own pace and they all gained something from it at different levels. And that's
}

what I think was really, really good. That there was no sort of, "Oh, I'm better than you," or "I won that game and you didn't." It was all very individual and I think they gained from that, I think they found that very valuable, that they could actually see improvement within themselves and not against other people.'

Important in creating a non-competitive, caring environment was the approach to the coaching, which emphasised and highlighted personal improvement and achievement by drawing attention to the positive aspects of each individual's play. In week three, Kitrina documented Richard's response to positive feedback:

'His face brightened when I talked about him looking athletic on the golf course. He seemed really pleased to have positive input about how he had played. He smiled a lot when I gave him encouragement and said a very warm "Thank you".'(KD field notes, 18 June)

Angela commented on Kitrina's approach:

'You [Kitrina] are very, you're approachable, and you're human and you have a laugh and you're not just standing there telling them what to do. But you're sort of part, you were part of it all... But you also had all this knowledge that none of the others of us had so you were a kind of central point really. But yeah, you were friendly and talkative and explained it, explained it well so everyone could understand.'

Julian supported this view when he reflected on the participants' responses to the coaching input:

'I think everyone mentioned that coaching's been good... It was softly, softly sort of thing, in a friendly way. It wasn't pressurised. It was broken down into nice parts, with a bit of humour. Just casually but not too casual.'

\section{Doing something normal}

As is common with sporting activity, the group also enjoyed the social experience - the having a coffee and a piece of cake after play. In Ronnie's words: 
I like being with people, you see, I like being social, I like having a laugh and stuff like that. I don't like sitting on my own with my thoughts.'

Like all groups, they told stories about their play: the good shots and the near misses. Some also mentioned telling their friends or family about their golf. Nurturing and encouraging this social time was, we felt, important to the success of the programme. It helped us get to know the group and the group members get to know each other. It was a time when the whole group could be together, and it appeared from the banter, jokes and laughs that this was an important part of the programme for the group members too. Richard's comments, for example, suggest that one of the main things that kept him coming each week was the chance to get out of the house and enjoy the 'banter in the bus, a cup of coffee, and a piece of cake'. Richard said it was fun hearing Harry and William verbally spar with each other, concluding: 'I'd like a bit of what they're on!'

In a sense, the golf programme gave the participants something positive to talk about outside their health problems - a way of taking a tentative step into a world beyond mental health problems. The importance of providing the group members with a route into 'normal' society was emphasised by André:

'The idea of getting an outsider, someone who plays golf professionally, people were really keen on that. Anything out of the system is brilliant... Away from the medical world, away from the institutions. You know, that's a really, really good thing. So people were quite impressed with that.'

\section{Factors threatening attendance}

Overall, there were no shared problems that threatened group members' attendance. However, four specific issues did arise for four individuals in the group. These issues illustrate the potential for individual responses and preferences about sport and physical activity settings to influence attendance.

\section{Crossing the bridge}

Although the focus of this project was mental health and an opportunity to enjoy the 'normal' activity of a round of golf at a local course with friends, there was one occasion where we believe a mental illness issue was a factor in one group member dropping out of the programme. In week four, the minibus took the most direct route to the golf course that went over a bridge. Although he gave no outward signs at the time, we later learned that Ali had a fear of crossing bridges. Ali had attended three consecutive sessions (weeks 2, 3 and 4) up to this point but did not attend any further sessions. Julian commented on Ali’s withdrawal from the programme:

Ali - I've got a feeling that it probably was my fault when we went over the bridge he got freaked out a bit. But I'm not sure, 'cause it cocktailed with him having a cold and backache so I don't know but every time I asked him he said he enjoyed it. I'm just thinking that's maybe why he stopped.'

\section{Texas scramble}

The move from the driving range to the course marked a move from learning to hit the ball to learning to play the game. At the driving range there are no penalties for miss-hit shots or misdirected balls. Once on the course, however, under traditional golf rules, a wayward shot must be played from wherever it lies. A 'Texas scramble' is an excellent way to help the beginner play round the course without getting disappointed by errant shots or getting bogged down continually looking for balls. All players hit off, but the next shot for every group member is played from where the best shot of the group finishes. This means bad shots can be picked up and put in a better position allowing play to continue more smoothly. The Texas scramble is also thought to foster team spirit as all golfers hit from the same spot every time and so have a vested interest in their team mates' play. For these reasons, a Texas scramble is often used with beginner groups.

Despite its worthy ethic, this approach to the game did not appeal to all members of the group. Harry had 
enthusiastically attended every session until the Texas scramble in week four. The following week he was absent. Our field notes at the next session attended by Harry offer some explanation:

'Harry was in the café when I arrived. I said, "We missed you last week.' He said, 'Sorry about that, I forgot - I went shopping.' He then went on to make a lengthy monologue the point of which was that golf was played with one's own ball - meaning the last time we went out we had played a Texas scramble.' (KD field notes, 16 July)

Harry confirmed his dislike of the Texas scramble game during a later interview: 'Being a previous golfer, I like to hit the ball from where it lies. And that game of Texas scramble, I didn't like it very much.'

\section{Time to move on}

For some members of the group, the opportunity to play golf was simply an opportunity to try something new and different. One member of the group who attended every session up until he started a college course commented that he was looking forward to the completion of the programme: not that there was anything wrong, but that it had served its purpose. Perhaps for some people learning to play golf is simply an activity that is different and fulfils a purpose for a set period of time. That they stop coming under these circumstances should not be viewed negatively but rather as a positive move for the individual into a new activity.

\section{Competition}

During the driving range session Kitrina suggested the group finish with a 'nearest the pin' game, where each group member took turns hitting to various targets. Most of the group appeared to enjoy the challenge, except Ronnie, who felt under unwanted pressure. Commenting on the golf programme as a whole, Ronnie singled out this competition as a negative experience:

'One thing I don't like is what we did [at the range] - we took in turns you see and I'm quite a shy person - I don't like having competition I just like enjoying myself... I don't like people hitting in a competition, who's winning, who's losing. I just like to enjoy and go with the flow you know.'

\section{Conclusion}

The programme described constitutes a first step, both in terms of research and practice, into exploring golf as a beneficial activity for people with severe and enduring mental health problems. While the findings are extremely positive on a number of levels, pointing to a range of possibilities for golf in mental health promotion, the extent to which they are generalisable is open to question. It is important, therefore, that future research develops this initial model in other mental health settings, and explores service users' perceptions of the acceptability and sustainability of golf as an activity form.

The positive responses from mental health professionals involved in the project strongly support the need for further initiatives in this area. Although low expectations among mental health professionals have been identified as a problem in some settings (Social Exclusion Unit, 2004), the findings of this research suggest that personal opinions on the suitability of an activity for service users need not influence its initiation or chances of success. Several mental health professionals revised their initial scepticism in light of the success of the project. For example, we asked Julian if he thought golf was a suitable activity for this client group:

\footnotetext{
'Oh definitely. Before this session, I would never have thought there would be so much interest in it. I would have thought golf would be a good one-off day out sort of thing, not so much eight weeks or so... But now I've seen it and now I've experienced it, it's brilliant. We plan to continue it, basically. If we can. If we can get the minibus and can organise it all. And we'll try to get it next Wednesday! I think it was a brilliant idea. It was really, really excellent. From the first session out, people concentrated and enjoyed it and everything. Yeah, it's one to continue! It's such a winning combination you wouldn't change it.'
} 
Katie was similarly positive in suggesting that the programme was worthy of continuation:

'Quite a few people said to me, "It's a shame its only nine weeks." I think some people would keep doing [it], carrying on really.'

When asked why the golf programme might not happen again, she replied: 'I think it's money, isn't it, probably? I think that's probably the big thing.' The final evidence for the success of this pioneering golf programme, and of the potential for similar programmes in the future, is the news that, one year on, and despite now having to contribute to the course fees, some of the original group members have continued to play, some new members have joined, and attendance has been good.

With thanks to Margot Hodgson for her enthusiasm in encouraging and facilitating this research as well as the other mental health professionals who assisted in organising and delivering the golf programme.

\section{References}

Anthony W (1993) Recovery from mental illness: the guiding vision of the mental health services system in the 1990s. Psychosocial Rehabilitation Journal 16 (4) 11-23.

Biddle SJH, Fox KR, Boutcher SH (eds) (2000) Physical activity and psychological well-being. London: Routledge.

Biddle SJH, Nigg CR (2000) Theories of exercise behavior. International Journal of Sport Psychology 31 (2) 290-304.

Brown S, Birtwistle J, Roe L et al (1999) The unhealthy lifestyle of people with schizophrenia. Psychological Medicine 29 (3) 697-701.

Carless D (2003) Mental health and physical activity in recovery. Doctoral dissertation. University of Bristol.

Carless D, Faulkner G (2002) Physical activity and mental health. In: McKenna J, Riddoch C (eds) Perspectives on health and exercise. Houndsmills: Palgrave MacMillan.

Chadwick PK (1997a) Schizophrenia: the positive perspective. London: Routledge.

Chadwick PK (1997b) Recovery from psychosis: learning more from patients. Journal of Mental Health 6 (6) 577-588.
Childs S, Griffiths C (2003) Severe and enduring mental illness. In: Everett T, Donaghy M, Feaver S (eds) Interventions for mental health. Edinburgh: Butterworth-Heinemann.

Department of Health (2004) At least five a week: a report from the Chief Medical Officer. London: HMSO.

Department of Health (2001) The journey to recovery: the government's vision for mental health care. London: Department of Health. www.doh.gov.uk/mentalhealth/journey.htm

Drake RE, Goldman HH, Leff HS (2001) Implementing evidence based practices in routine mental health service settings. Psychiatric Services 52 179-182.

Faulkner A (1997) Knowing our own minds. London: Mental Health Foundation.

Faulkner A (2002) User-led research. In: Sainsbury Centre for Mental Health. Working for inclusion. London: SCMH.

Faulkner G, Biddle S (1999) Exercise as an adjunct treatment for schizophrenia: a review of the literature. Journal of Mental Health 8 (5) 441-457.

Faulkner G, Sparkes A (1999) Exercise as therapy for schizophrenia: an ethnographic study. Journal of Sport \& Exercise Psychology 21 (1) 52-69.

Fox KR (1999) The influence of physical activity on mental wellbeing. Public Health Nutrition 2 411-418.

Cabinet Office (2002) Game plan: a strategy for delivering Government's sport and physical activity initiatives. London: The Strategy Unit. http://www.number-10.gov.uk/su/sport/report/ pdf.htm

Green AI, Patel JK, Goisman RM et al (2000) Weight gain from novel antipsychotic drugs: need for action. General Hospital Psychiatry 22 (4) 224-235.

Mass KW (2001) Media promotion of the paradigm citizen/golfer: an analysis of golf magazines' representation of disability, gender and age. Sociology of Sport Journal 18 (1) 21-36.

Maykut P, Morehouse R (1994) Beginning qualitative research. London: The Falmer Press.

McPherson BD, Curtis JE, Loy JW (1989) The social significance of sport. Champaign, Ill: Human Kinetics.

Mental Health Foundation (2000) Strategies for living: a report of userled research into people's strategies for living with mental distress. London: Mental Health Foundation.

Miles MB, Huberman AM (1994) Qualitative data analysis. Thousand Oaks, CA: Sage.

Miller WL, Crabtree BF (2000) Clinical research. In: Denzin NK, Lincoln YS (eds) The handbook of qualitative research. 2nd edition. Thousand Oaks, CA: Sage. 
Morgan WP (ed) (1997) Physical activity and mental health. Washington DC: Taylor and Francis.

Repper J, Perkins R (2003) Social inclusion and recovery. Edinburgh: Ballière Tindall.

Sartorius N (2000) Why bother about stigma because of schizophrenia? Lily Psychiatry lecture. Annual meeting of the Royal College of Psychiatrists, Edinburgh.

Social Exclusion Unit (2004) Mental health and social exclusion. London: Office of the Deputy Prime Minister.

Tudor K (1996) Mental health promotion: paradigms and practice. London: Routledge.

Van Landuyt LM, Ekkekakis P, Hall EE et al (2000) Throwing the mountains into the lakes: on the perils of nomothetic conceptions of the exercise-affect relationship. Journal of Sport \& Exercise Psychology 22 208-234.
Whitehead JR, Corbin CB (1997) Self-esteem in children and youth: the role of sport and physical education. In: Fox KR (ed) The physical self: from motivation to well-being. Champaign, Ill: Human Kinetics.

Wing JK (1978) Schizophrenia: towards a new synthesis. London: Academic Press.

Wallcraft J (1998) Healing minds: a report on current research, policy and practice concerning the use of complementary and alternative therapies for a wide range of mental health problems. London: Mental Health Foundation.

\section{Contact:}

David Carless e david.carless@bristol.ac.uk Kitrina Douglas e k.douglas@bristol.ac.uk

\section{EVENTS DIARY}

Title: Enhancing lives - improving links between community renewal, social care and health Pavilion in partnership with BASW and supported by the Neighbourhood Renewal Unit, Office of the Deputy Prime Minister

Date: Thursday 24 February 2005

Venue: Central London

Title: Managing new realities - personalising services through integrated health, housing and social care provision

In association with The Guardian

Date: Wednesday 2 and Thursday 3 March 2005

Venue: Victoria Park Plaza Hotel, London

Title: Mental Health Today Scotland exhibition 2005 - Connecting people in mental health In association with Care and Health

Date: Wednesday 9 March 2005

Venue: Moat House Hotel, Glasgow

Title: Young Lives Today Manchester Exhibition 2005

In association with SACCS and Society Guardian

Date: Wednesday 9 March 2005

Venue: Manchester International Convention Centre

Title: Modernisation of mental health day services - a national conference to examine the new social inclusion policy framework

Date: Thursday 17 March 2005

Venue: London Voluntary Sector Resource Centre, London
(Please note these details were correct at the time of printing. Changes may occur)

Title: Drugs and alcohol today - responses to the future

In association with SocietyGuardian and Turning Point

Date: Wednesday 6 April 2005

Venue: Business Design Centre, Islington, London

Title: Overfed and undernourished - a national conference on nutritional strategies for tackling childhood obesity

Date: Tuesday 12 April 2005

Venue: ORT House Conference Centre, London

Title: Black women and mental health - from the margins to the mainstream In association with Change4Life

Date: Friday 22 April 2005

Venue: ORT House Conference Centre, London

For further information on the above conferences please contact Pavilion:

Tel (UK): 08701613505

Tel (non-UK): +44 1273623222

Fax (UK): 08701613506

Fax (non-UK): +44 1273625526 or Email: info@pavpub.com

Book online at www.pavpub.com and view our events diary.

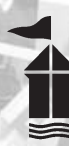

Pavilion

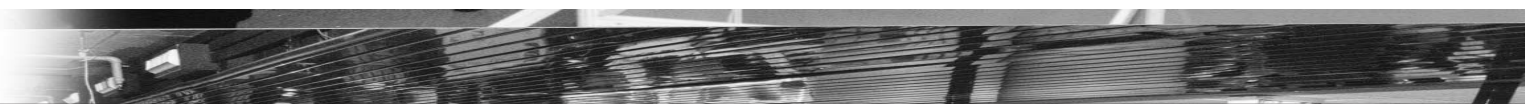

